\title{
Chemistry and pharmacology of the herb pair Flos Lonicerae japonicae-Forsythiae fructus
}

\author{
Yi-ping Guo, Li-gen Lin ${ }^{*}$ and Yi-tao Wang*
}

\begin{abstract}
The Chinese medicine herb pair Flos Lonicerae japonicae (FLJ) and Forsythiae fructus (FF), is a representative heat-clearing (qing re) and detoxifying (jie du) combination that exhibits many pharmacological activities, including antibacterial, antiviral, antitumor, anti-inflammatory, and antioxidant effects. Extensive phytochemical studies have identified a series of bioactive compounds, such as chlorogenic acid from FLJ and forsythoside A from FF. This article provides a comprehensive review on the chemical and pharmacological principles of the traditional functions of FLJ-FF, and sheds light on further developments of this herb pair.
\end{abstract}

\section{Introduction}

Although Chinese medicine (CM) often uses multicomponent formulations and the actions of each component on multiple targets [1], the use of herb pairs-the unique clinical combination of two relatively fixed herbs-is the simplest and most fundamental form of multiherb therapy aimed at specific efficacy. The role of herb pairs has been explained by the yin and yang and five-phase theories [2], and by reference to the broader philosophical and cultural frameworks that emphasize balance between bodily functions and environmental conditions [3]. Herb pairs are simpler in composition than complete formulae but still therapeutically effective. There are several aims and principles of herbal compatibility, sometimes called the "seven relations of CM": singular application, mutual promotion, mutual assistance, mutual restraint, mutual detoxification, mutual inhibition, and mutual intoxication [4]. The principle of mutual promotion explains why herb pairs have significantly better pharmacological efficacy than individual herbs, a principle that is applied in many famous herb formulae, such as Yinqiao San [1]. Recent pharmacological investigation has clarified this mutual effect [5].

The herb pair of Flos Lonicerae japonicae (FLJ) and Forsythiae fructus (FF) has been widely used to cure febrile illness (e.g., cold and flu) at the primary stage [6]. FLJ is the flower bud of Lonicera japonica Thunb and FF is the dried fruit of Forsythia suspensa. Yinqiao San, which

\footnotetext{
*Correspondence: ligenl@umac.mo; ytwang@umac.mo

State Key Laboratory of Quality Research in Chinese Medicine, Institute of Chinese Medical Sciences, University of Macau, Avenida da Universidade, Macau, SAR, China
}

(c) 2015 Guo et al. This is an Open Access article distributed under the terms of the Creative Commons Attribution License (http://creativecommons.org/licenses/by/4.0), which permits unrestricted use, distribution, and reproduction in any medium, provided the original work is properly credited. The Creative Commons Public Domain Dedication waiver (http:// creativecommons.org/publicdomain/zero/1.0/) applies to the data made available in this article, unless otherwise stated. contains FLJ and FF with a crude weight ratio of 1:1, is used for detoxification and relieving internal heat and fever [7]. Nowadays, the various available dosage forms of FLJ-FF herb pair, such as capsules, powder, oral decoctions, and granules, are mainly indicated for cold, fever, and even upper respiratory tract infection [8]. The most familiar ones are Vc Yinqiao tablet and Shuanghuanglian oral decoction [9]. However, the mechanisms of the formulae have not been completely elucidated, and research on this combination has rarely been summarized. This article aims to provide a comprehensive and up-todate review of phytochemical and pharmacological studies of FLJ and FF.

\section{Review}

Ethnopharmacological use of the Yinqiao herb pair

The FLJ-FF herb pair is described as light (qing) and floating (fu), and able to clear heat, combat swelling, and cure boils $[10,11]$. It has been widely used as an antipyretic, antidotal, and anti-inflammatory agent for the treatment of infections such as acute nephritis and erysipelas.

\section{Chemical constituents of FLJ and FF}

More than 140 compounds have been isolated from FLJ, including flavonoids, iridoids, organic acids, and saponins. Compounds identified from FLJ are listed in Table 1, including chlorogenic acid, luteolin, loganin, and loniceroside A. One kind of important chemical component of FLJ is its volatile oil; hexadecanoic acid, octadecadienoic acid, ethyl palmitate, and dihydrocarveol are the main fatty 
Table 1 Chemical constituents of Lonicera japonica Thunb

\begin{tabular}{|c|c|}
\hline No. & Compounds \\
\hline \multicolumn{2}{|c|}{ Organic acids } \\
\hline 1 & chlorogenic acid \\
\hline 2 & isochlorogenic acid \\
\hline 3 & caffeic acid \\
\hline 4 & hexadecanoic acid \\
\hline 5 & myristic acid \\
\hline 6 & 3,5-O-dicaffeoylquinic acid \\
\hline 7 & 4,5-O-dicaffeoylquinic acid \\
\hline 8 & 3,4-O-dicaffeoylquinic acid \\
\hline 9 & 1,3-O-dicaffeoylquinic acid \\
\hline 10 & 3-ferulicoylquinic \\
\hline 11 & 4-ferulicoylquinic \\
\hline 12 & 5-O-caffeoylquinic acid \\
\hline 13 & 4-O-caffeoylquinic acid \\
\hline 14 & caffeoyl- $\mathrm{CH}_{2}-\mathrm{O}$-quinic acid \\
\hline 15 & 1,5-O-dicaffeoylquinic acid \\
\hline 16 & 1,4-O-dicaffeoylquinic acid \\
\hline 17 & methylated dicaffeoylquinic acid \\
\hline 18 & $\begin{array}{l}\text { oleanolic acid 28-a-O-L-rhamnopyranosyl- } \\
(1 \rightarrow 2) \text {-[ }[\beta-\delta \text {-dxylopyranosyl }(1 \rightarrow 6)] \text { - } \\
\beta \text { - } \delta \text {-glu-copyranosyol ester }\end{array}$ \\
\hline 19 & 3,5-O-dicaffeoylquinic acid \\
\hline 20 & methyl chlorogenate \\
\hline 21 & 3-O-caffeoylquinic acid butyl ester \\
\hline 22 & 3-O-caffeoylquinic acid \\
\hline 23 & 3-caffeoylquinic acid methyl ester \\
\hline 24 & 3,5-dicaffeoylquinic acid butyl ester \\
\hline 25 & $\begin{array}{l}\text { vanillic acid 4-O- } \beta-\delta-(6-O- \\
\text { benzoylglucopyranoside) }\end{array}$ \\
\hline 26 & protocatechuic acid \\
\hline 27 & chlorogenic acid butyl ester \\
\hline 28 & chlorogenin tetraacetate \\
\hline 29 & 5 -feruloylquinic acid \\
\hline 30 & methyl 3,5-di-O-caffeoylquinic acid \\
\hline 31 & methyl 3,4-di-O-caffeoylquinic acid \\
\hline 32 & caffeic acid methyl ester \\
\hline \multicolumn{2}{|c|}{ Flavonoids } \\
\hline 33 & chrysoeriol \\
\hline 34 & chrysoeirol-7-O-neohesperidoside \\
\hline 35 & luteolin \\
\hline 36 & chrysoeriol 7-O- $\beta-\delta$-glucopyranoside \\
\hline 37 & isorhamnetin 3-O- $\beta-\delta$-glucopyranoside \\
\hline 38 & isorhamnetin 3-O- $\beta-\delta$-rutinoside \\
\hline 39 & kaempferol 3-O- $\beta$ - $\delta$-glucopyranoside \\
\hline 40 & kaempferol 3-O- $\beta$ - $\delta$-rutinoside \\
\hline
\end{tabular}
Resource
Table 1 Chemical constituents of Lonicera japonica Thunb Ref. (Continued)

\begin{tabular}{|c|c|c|c|c|}
\hline & & 41 & quercetin 3-O- $\beta-\delta$-glucopyranoside & Flowers \\
\hline Whole plant & [39] & 42 & luteolin 7-O-a- $\delta$-glucoside & Flowers \\
\hline Whole plant & [39] & 43 & luteolin-7-O- $\beta-\delta$-galactoside & Flowers \\
\hline Flower & {$[57]$} & 44 & hyperoside & Aerial parts \\
\hline Whole plant & {$[60]$} & 45 & Ionicerin & Whole plant \\
\hline Whole plant & {$[60]$} & 46 & hydnocarpin & Aerial parts \\
\hline Whole plant & {$[61]$} & 47 & quercetin & Aerial parts \\
\hline Whole plant & {$[61]$} & 48 & astragalin & Aerial parts \\
\hline Whole plant & {$[61]$} & 49 & isoquercitrin & Aerial parts \\
\hline Whole plant & {$[61]$} & 50 & rhoifolin & Aerial parts \\
\hline Whole plant & {$[61]$} & 51 & flavoyadorinin-B & Aerial parts \\
\hline Whole plant & {$[61]$} & 52 & rutin & Flowers buds \\
\hline Whole plant & {$[62]$} & 53 & tricin-7-O- $\beta$-d-glucoside & Flowers buds \\
\hline Whole plant & {$[62]$} & 54 & chrysin & Leaves \\
\hline Whole plant & {$[62]$} & 55 & eriodictyol & Aerial parts \\
\hline Whole plant & {$[62]$} & 56 & apigenin & Aerial parts \\
\hline Whole plant & {$[62]$} & 57 & corymbosin & Aerial parts \\
\hline Whole plant & {$[62]$} & 58 & 5-hydroxy-3, 4,7-trimethoxylflavone & Aerial parts \\
\hline \multirow[t]{2}{*}{ Flowers } & [57] & 59 & ochnaflavone & Whole plant \\
\hline & & 60 & ochnaflavone 4'-O-methyl ether & Aerial parts \\
\hline Flower buds & {$[63]$} & \multicolumn{3}{|c|}{ Iridoids } \\
\hline Flower buds & {$[63]$} & 61 & loganin & Whole plant \\
\hline Flower buds & [64] & 62 & sweroside & Flower buds \\
\hline Flower buds & {$[65]$} & 63 & 7-O-ethyl sweroside & Flower buds \\
\hline Flower buds & {$[65]$} & 64 & 7-epivogeloside & Flower buds \\
\hline Flower buds & [65] & 65 & secoxyloganin & Flower buds \\
\hline \multirow[t]{2}{*}{ Flower buds } & {$[63]$} & 66 & secoxyloganin 7-butyl ester & Flower buds \\
\hline & & 67 & 7-dimethyl-secologanoside & Flower buds \\
\hline Flowers & [39] & 68 & centauroside & Flower buds \\
\hline Flower buds & [35] & 69 & secologanic acid & Flower buds \\
\hline Flower buds & {$[66]$} & 70 & secologanin & Flower buds \\
\hline Aerial Parts & {$[67]$} & 71 & secologanin dimethyl acetal & Flower buds \\
\hline Whole plant & {$[36]$} & 72 & kingiside & Flower buds \\
\hline Whole plant & {$[36]$} & 73 & vogeloside & Flower buds \\
\hline \multirow[t]{2}{*}{ Whole plant } & {$[37]$} & 74 & epi-vogeloside & Flower buds \\
\hline & & 75 & dehydrormorroniside & Flower buds \\
\hline Flowers & {$[57]$} & 76 & ketologanin & Flower buds \\
\hline Aerial parts & {$[57]$} & 77 & 7a-morroniside & Flower buds \\
\hline Flowers & {$[57]$} & 78 & $7 \beta$-morroniside & Flower buds \\
\hline Flowers & {$[57]$} & 79 & secologanoside & Flower buds \\
\hline Flowers & {$[57]$} & 80 & Ionijaposide A & Flower buds \\
\hline Flowers buds & {$[35]$} & 81 & Ionijaposide B & Flower buds \\
\hline Flowers & {$[57]$} & 82 & lonijaposide C & Flower buds \\
\hline Flowers buds & {$[35]$} & 83 & Ionijaposide D & Flower buds \\
\hline
\end{tabular}


Table 1 Chemical constituents of Lonicera japonica Thunb (Continued)

\begin{tabular}{ll}
\hline 84 & Ionijaposide E \\
85 & Ionijaposide F \\
86 & Ionijaposide G \\
87 & Ionijaposide H \\
88 & Ionijaposide I \\
89 & Ionijaposide J \\
90 & Ionijaposide K \\
91 & Ionijaposide L \\
92 & I-phenylalaninosecologanin \\
93 & 7-O-(4-ß-d-glucopyranosyloxy-3-methoxy- \\
& benzoyl) secologanolic acid \\
94 & 6'-O-(7a-hydroxyswerosyloxy) loganin \\
95 & (Z)-aldosecologanin \\
96 & (E)-aldosecologanin \\
97 & loniceracetalide A \\
98 & Ioniceracetalide B
\end{tabular}

Saponins

99 3-O-a-L-arabinopyranosyl-28-O-[ $[\beta-d-$ glucopyranosyl $(1 \rightarrow 6)-\beta$-dglucopyranosyl] oleanolic acid

100 3-O-[a-L-rahmnopyranosyl $(1 \rightarrow 2)$-a-larabinopyranosyl]-28-O- $\beta$-dglucopyran-Osyl hederagenin

101 3-O-[a-l-rahmnopyranosyl $(1 \rightarrow 2)$-a-Iarabinopyranosyl]-28-O-[ßdglucopyranosyl( $1 \rightarrow 6)-\beta$-d-glucopyranosyl] oleanolic acid

102 3-O-[a-I-rahmnopyranosyl ( $1 \rightarrow$ 2)-a--arabinopyranosyl]-2 8-0-[6-acetyl-dglucopyranosyl ( $1 \rightarrow 6$ )-a-d-glucopyranosyl] hederagenin

103 3-O-a-I-rhamnopyranosyl-(1 $\rightarrow$ 2)-a-Iarabinopyranosy hederagenin $28-O-\beta-d-$ xylpyranosyl ( $1 \rightarrow 6$ )- $\beta$-d-glucopyranosyl ester

104 3-O-a-l-arabinopyranosy hederagenin 28-O-ad-rhamnopyranosyl $(1 \rightarrow 2)[\delta$-d-xyl pyranosyl $(1 \rightarrow 6)-\beta$-d-glucopyranosyl ester

105 3-O-a-I-rhamnopyranosyl-( $1 \rightarrow 2)-\alpha-\mid-$ arabinopyranosy hederagenin $28-O-\beta-d-$ rhamnopyranosyl $(1 \rightarrow 2)[\beta-d$-xylpyranosyl $(1 \rightarrow 6)-\beta$-d-glucopyranosyl ester

106 3-O- $\beta$-d-glucopyranosyl-(1 $\rightarrow$ 4)- $\beta$-Iglucopyranosyl $(1 \rightarrow 3)$-a-Irhamnopyranosyl $(1 \rightarrow 2)-a-1-a r a b i n o p y r a n o s y h e d e r a g e n i n 28-O-$ $\beta$-d-glucopyranosyl- $(1 \rightarrow 6)-\beta-d-$ glucopyranosyl ester

107 Hederagenin-3-O-a-I-rhamnopyranosyl $(1 \rightarrow 2)$ a-larabinopyranoside

108 3-O-a-l-rhamnopyranosyl- $(1 \rightarrow 2)-a-\mid-$ arabinopyranosy hederagenin $28-0-\beta-d-$ glucopyranosyl ( $1 \rightarrow 6$ )- $\beta$-d-glucopyranosyl ester

\begin{tabular}{|c|c|c|c|c|c|}
\hline Flower buds & {$[78]$} & 109 & & Flower buds & {$[81]$} \\
\hline Flower buds & {$[78]$} & & $\begin{array}{l}\text { rhamnopyranosyl( }(\rightarrow 2) \text {-a-larabino pyranosyl } \\
\text { hederagenin } 28-O-\beta-d-\text { glucopy ranosyl- }\end{array}$ & & \\
\hline Flower buds & {$[78]$} & & $(1 \rightarrow 6)-\beta$-d-glucopyranosyl ester & & \\
\hline Flower buds & {$[78]$} & 110 & loniceroside A & Whole plant & {$[75]$} \\
\hline Flower buds & [78] & 111 & loniceroside B & Whole plant & {$[75]$} \\
\hline Flower buds & {$[78]$} & 112 & loniceroside C & Aerial parts & {$[82]$} \\
\hline Flower buds & {$[78]$} & 113 & loniceroside D & Flower buds & [83] \\
\hline Flower buds & {$[78]$} & 114 & loniceroside E & Flower buds & {$[83]$} \\
\hline Stems,leaves & [79] & 115 & macranthoidin A & Flower buds & [64] \\
\hline Stems,leaves & {$[79]$} & 116 & macranthoidin B & Flower buds & {$[64]$} \\
\hline & & 117 & dipsacoside B & Flower buds & {$[64]$} \\
\hline Stems,leaves & {$[79]$} & 118 & hederagenin-28-0-[3-d-glucopyranosyl- & Flower buds & 4] \\
\hline Stems,leaves & {$[79]$} & & $(1 \rightarrow 6)-\beta$-d-glucopyranosyl] ester & & \\
\hline Stems,leaves & {$[79]$} & 119 & macranthoside $B$ & Flower buds & {$[64]$} \\
\hline Flower buds & {$[76]$} & 120 & macranthoside A & Flower buds & {$[64]$} \\
\hline Flower buds & {$[76]$} & 121 & $\begin{array}{l}\text { 3-O-[a-l-rhamnopyranosyl-( }(1 \rightarrow 2)-a-\mid- \\
\text { arabinopyranosyl] hederagenin }\end{array}$ & Flower buds & {$[64]$} \\
\hline ial parts & {$[80]$} & 122 & saponin 1 & Flower buds & {$[62]$} \\
\hline & & 123 & saponin 4 & Flower buds & {$[62]$} \\
\hline & & 124 & hederagenin 3-O-a-I-arabinopyranoside & Flowers & {$[57]$} \\
\hline Aerial parts & {$[80]$} & 125 & hederagenin & Whole plant & {$[70]$} \\
\hline & & 126 & oleanolic acid & Flower buds & {$[35]$} \\
\hline Aerial parts & {$[80]$} & Othe & & & \\
\hline & & 127 & lonijaposide A1 & Flowers & {$[72]$} \\
\hline & & 128 & lonijaposide A2 & Flowers & {$[72]$} \\
\hline Aerial parts & {$[80]$} & 129 & lonijaposide A3 & Flowers & {$[72]$} \\
\hline & & 130 & lonijaposide A4 & Flowers & {$[72]$} \\
\hline & & 131 & Ionijaposide B1 & Flowers & {$[72]$} \\
\hline Flower buds & {$[66]$} & 132 & Ionijaposide B2 & Flowers & {$[72]$} \\
\hline & & 133 & 5-hydroxymethyl-2-furfural & Flowers & {$[57]$} \\
\hline Flower buds & {$[66]$} & 134 & 1-O-methyl-myo-inositol & Flower buds & {$[35]$} \\
\hline & & 135 & nonacontane & Flower buds & {$[35]$} \\
\hline Flower buds & {$[66]$} & 136 & $\beta$-sitosterol & Flower buds & {$[35]$} \\
\hline & & 137 & sucrose & Flower buds & {$[35]$} \\
\hline & & 138 & glucose & Flower buds & {$[35]$} \\
\hline Flower buds & {$[81]$} & 139 & shuangkangsu & Flower & {$[59]$} \\
\hline & & 140 & $\begin{array}{l}\text { (+)-N-(3-methybutyryl- } \beta \text {-d-glucopyranoyl)- } \\
\text { nicotinate }\end{array}$ & Flower buds & {$[78]$} \\
\hline & & 141 & $\begin{array}{l}\text { (+)-N-(3-methybut-2-enoyl- } \beta \text {-d-glucopyranoyl)- } \\
\text { nicotinate }\end{array}$ & Flower buds & {$[78]$} \\
\hline Flower buds & [81] & 142 & 5'-O-methyladenosine & Flower buds & {$[78]$} \\
\hline Flower buds & [81] & 143 & guanosine & Flower buds & {$[78]$} \\
\hline & & 144 & adenosine & Flower buds & {$[78]$} \\
\hline & & 145 & syringin & Flower buds & [78] \\
\hline
\end{tabular}

Table 1 Chemical constituents of Lonicera japonica Thunb (Continued) 
acids identified through gas chromatography-mass spectrometry [12].

More than 100 compounds have been identified from FF, including alkaloids, flavonoids, phenylethanoid glycosides, triterpenoids, and lignans (Table 2). The major constituents of FF include quercetin, rutaecarpine, forsythiaside A, betulinic acid, and forsythialan A. According to the China Pharmacopoeia (2005 edition), forsythin is a chemical marker for quality control of FF. Recent pharmacological research indicates that forsythiaside, forsythin, and rutin are responsible for the biological activities of FF [13]. Thus, the use of forsythin as a single marker for FF quality control is likely to lead to biased assessment. Quantification of both forsythiaside and forsythin in FF is important for the evaluation of this herb's quality. In the 2010 edition of the China Pharmacopoeia, both forsythin and forsythiaside were specified as FF quality control markers.

\section{Pharmacological effects}

Forsythoside A has strong antioxidant, antibacterial, and antiviral activities [14]. Forsythiaside exhibits strong antibacterial, antiviral, antioxidant, anti-inflammatory, and cyclic adenosine monophosphate phosphodiesterase inhibitory effects [15]; forsythin and rutin show a strong antioxidant effect [16]. In addition, chlorogenic acid possesses antibacterial and antiviral activities [17]. The bioactive properties of FLJ and FF are summarized below in terms of traditional functions and modern pharmacological findings.

\section{Effects of the FLJ-FF herb pair}

Studies of the synergistic action of the FLJ-FF herb pair are rare. There is little evidence for its synergistic properties, although Li et al. [18] reported a synergistic antiinflammatory effect. They established a rat model of chronic obstructive pulmonary disease and treated the animals with FLJ-FF herb pair extract (FLJ:FF, 2:3) and a single herb extract. FLJ-FF herb pair treatment improved chronic obstructive pulmonary disease pathological changes and significantly reduced interleukin- $1 \beta$ (IL-1 $\beta$ ) levels in bronchoalveolar lavage fluid compared with each single herb. Duan et al. [19] evaluated anti-free radical activity of the FLJ-FF herb pair using a rat fever model. They divided Sprague-Dawley rats into different groups, treated some groups with $20 \%$ dilute yeast suspension to create a fever model, and then tested the effectiveness of different drug combinations. The FLJ-FF herb pair showed potent free radical cleavage activity. Using microbial-plate methods, Wang et al. [20] found the FLJ-FF herb pair at the ratio of 1:6 showed the most significant inhibitory effect on Streptococcus suis 2. These studies indicate that FLJ and FF show stronger bioactivity in combination than alone.
Table $\mathbf{2}$ Chemical constituents of Forsythiae fructus

\begin{tabular}{|c|c|c|}
\hline No. & Compounds & Ref. \\
\hline \multicolumn{3}{|c|}{ Phenylethanoid Glycosides } \\
\hline 146 & forsythoside A & [84] \\
\hline 147 & forsythoside B & [85] \\
\hline 148 & forsythoside C & [85] \\
\hline 149 & forsythoside D & [85] \\
\hline 150 & forsythoside E & [86] \\
\hline 151 & forsythoside F & [86] \\
\hline 152 & isoforsythoside & {$[87]$} \\
\hline 153 & forsythoside $\mathrm{H}$ & [86] \\
\hline 154 & forsythoside I & [86] \\
\hline 155 & forsythoside J & [86] \\
\hline 156 & $R$-forsythoside J & [88] \\
\hline 157 & S-forsythoside J & {$[88]$} \\
\hline 158 & $R$-suspensaside & [88] \\
\hline 159 & S-suspensaside & [88] \\
\hline 160 & S-suspensaside methyl ether & [88] \\
\hline 161 & calceolarioside A & [89] \\
\hline 162 & calceolarioside B & [86] \\
\hline 163 & plantainoside A & [89] \\
\hline 164 & suspensaside A & [90] \\
\hline 165 & lianqiaoxinoside B & {$[54]$} \\
\hline 166 & salidroside & [91] \\
\hline 167 & 3,4-dihydroxyphenyl alcohol-8-o- $\beta$-D-glucopyranoside & [90] \\
\hline 168 & forsythenside A & [35] \\
\hline 169 & forsythenside F & [35] \\
\hline 170 & $\begin{array}{l}\text { phenethylalcohol- } \beta \text {-D-xylopyranosyl-(1-6)- } \beta-D- \\
\text { glucopyranoside }\end{array}$ & [35] \\
\hline \multicolumn{3}{|c|}{ Triterpenoids } \\
\hline 171 & isobauerenyl acetate & [90] \\
\hline 172 & ocotillone & [90] \\
\hline 173 & ocotillol acetate & [90] \\
\hline 174 & 20(S)-dammar-24-ene-3ß,20-diol-3-acetate & [92] \\
\hline 175 & oleanolic acid & [93] \\
\hline 176 & $\beta$-amyrinacetate & [92] \\
\hline 177 & ursolic acid & [93] \\
\hline 178 & 2a,3a-hydroxyursolic acid & [94] \\
\hline 179 & 2a,23-hydroxyursolic acid & [93] \\
\hline 180 & betulinic acid & [95] \\
\hline 181 & 3ß-acetylbetulinic acid & [95] \\
\hline 182 & 2a-hydroxybetulinic acid & [93] \\
\hline 183 & 3ß-acetyl-20,25-epoxydammarane-24a-ol & {$[96]$} \\
\hline 184 & $3 \beta$-acetyl-20,25-epoxydammarane-24ß-ol & [96] \\
\hline 185 & onjisaponin F & [94] \\
\hline 186 & onjisaponin G & [94] \\
\hline
\end{tabular}


Table 2 Chemical constituents of Forsythiae fructus (Continued)

\begin{tabular}{|c|c|}
\hline Lign & ans \\
\hline 187 & $(-)$ arctigenin \\
\hline 188 & (-) dimethylmatairesinol \\
\hline 189 & (+) phillygenin \\
\hline 190 & (+) phillyrin (forsythin) \\
\hline 191 & (+) epipinoresinol \\
\hline 192 & (+) epipinoresinol-4-O- $\beta$-D-glucoside \\
\hline 193 & (+) epipinoresinol-4'-O- $\beta$-D-glucoside \\
\hline 194 & (+)-1-hydroxy-6-epipinoresinol \\
\hline 195 & (+)-1-hydroxy-6-epipinoresinol-4"-O- $\beta$-D-glucopyranoside \\
\hline 196 & 7'-epi-8-hydroxypinoresinol \\
\hline 197 & (+) pinoresinol \\
\hline 198 & (+) pinoresinol- $\beta$-D-glucoside \\
\hline 199 & (+) pinoresinol monomethyl ether- $\beta$-D-glucoside \\
\hline 200 & (+)-1-hydroxypinordsinol \\
\hline 201 & (+)-1-hydroxypinordsinol-4'-O- $\beta$-D-glucoside \\
\hline 202 & (+)-1-hydroxypinordsinol-4"-O- $\beta$-D-glucoside \\
\hline 203 & 8-hydroxypinoresinol \\
\hline 204 & isolariciresinol \\
\hline 205 & isolariciresinol-4-O- $\beta$-D-glucopyranoside \\
\hline 206 & isolariciresinol-9'-O- $\beta$-D-glucopyranoside \\
\hline 207 & (+)-isoolivil \\
\hline & cedrusin \\
\hline 209 & benzenebutanoic acid \\
\hline 210 & olivil \\
\hline & (+) lariciresinol \\
\hline 212 & forsythialan A \\
\hline 213 & forsythialan B \\
\hline Irido & id Glycosides \\
\hline 214 & adoxosidic acid \\
\hline C6-C & 2 Natural Alcohols \\
\hline 215 & rengyol \\
\hline 216 & isorengyol \\
\hline 217 & rengyoside A \\
\hline 218 & rengyoside $\mathrm{C}$ \\
\hline 219 & suspenol \\
\hline 220 & rengyolester \\
\hline 221 & rengynic acid \\
\hline 222 & rengynic acid 1'-O- $\beta$-D-glucoside \\
\hline 223 & rengyoxide \\
\hline 224 & rengyoside B \\
\hline 225 & rengyolone \\
\hline 226 & cornoside \\
\hline 227 & forsythenside B \\
\hline
\end{tabular}

Table 2 Chemical constituents of Forsythiae fructus (Continued)

\begin{tabular}{|c|c|c|}
\hline \multicolumn{3}{|c|}{ Flavonoids } \\
\hline 228 & quercetin & [105] \\
\hline 229 & hyperin & [106] \\
\hline 230 & rutin & [105] \\
\hline 231 & wogonin-7-O-glucoside & {$[98]$} \\
\hline 232 & hesperidin & [106] \\
\hline \multicolumn{3}{|c|}{ Alkaloids } \\
\hline 233 & rutaecarpine & [107] \\
\hline 234 & suspensine A & [108] \\
\hline 235 & (-)-egenine & [108] \\
\hline 236 & (-)-7'-O-methylegenine & [108] \\
\hline 237 & (-)-bicuculline & [108] \\
\hline 238 & octahydro-1H, 5H-dipyrrolo [1,2-a:1',2'-d] pyrazine & [109] \\
\hline \multicolumn{3}{|c|}{ Others } \\
\hline 239 & stearic acid & {$[16]$} \\
\hline 240 & palmitic acid & {$[16]$} \\
\hline 241 & vanillic acid & {$[90]$} \\
\hline 242 & caffeic acid & {$[90]$} \\
\hline 243 & 4-methoxycaffeic acid & [100] \\
\hline 244 & chlorogenic acid & [106] \\
\hline 245 & 4-caffeoylrutinose & {$[98]$} \\
\hline 246 & suspenolic acid & {$[98]$} \\
\hline 247 & 3-ethyl-7-hydroxyphthalide & {$[67]$} \\
\hline 248 & forsythenin & {$[90]$} \\
\hline 249 & tannic acid & [110] \\
\hline
\end{tabular}

\section{Detoxifying: antibacterial action}

[101] FF is a broad-spectrum antimicrobial agent used mainly for upper respiratory tract infection and acute nephritis [90] $[10,11]$. Previous studies have shown that the antibacterial ingredients of Forsythia species are concentrated in lignans, phenylethanoid glycosides, and volatile oil. Endo et al. [21, 22] investigated the antibacterial [102] principle of F. suspensa leaves, and found that forsytho[91] sides A, B, C, and D showed antibacterial activity against [91] Staphylococcus aureus at $<2 \mu \mathrm{M}$. In 2005, the effect of $F$. [84] suspensa volatile oil against Saccharomyces cerevisiae, [103] Penicillium chrysogenum, and Aspergillus niger was esti[98] mated by paper dispersion method. The minimal bacteri[98] cidal concentrations $(\mathrm{MBC})$ were $3.91 \times 10^{-4} \mathrm{~mL} / 100 \mathrm{~mL}$, [98] $7.81 \times 10^{-4} \mathrm{~mL} / 100 \mathrm{~mL}$, and $3.13 \times 10^{-3} \mathrm{~mL} / 100 \mathrm{~mL}$, [104] respectively [23]. Chen's group [11] investigated the thera[91] peutic effect of FF ethanol extract on Salmonella typhi[91] murium infection in mice. The survival rate of mice [104] treated by FF ethanol extract was higher than in the con[90] trol group; the numbers of viable bacteria in spleen and the spleen weight index were much lower in the treatment group. Furthermore, the levels of immunoglobulin G and 
interferon $\gamma$ increased in the treatment group, compared with the control group. The survival rate of the infected mice was as high as $70 \%$ when the therapeutic dose of FF ethanol extract was $30 \mathrm{~g} / \mathrm{kg} /$ day, which demonstrates a significant relationship between input (dose) and output (effect) $(\mathrm{P}<0.05)$. All of the above studies support the traditional use of $\mathrm{FF}$ as an antibacterial agent.

The antibacterial activity of FLJ has been comprehensively studied. In 2009, Rahman et al. [12] evaluated the antibacterial potential of FLJ volatile oil, which showed a remarkable antibacterial effect against Listeria monocytogenes (ATCC 19116), Bacillus subtilis (ATCC 6633), Bacillus cereus SCK 111, Staphylococcus aureus (ATCC 6538 and KCTC 1916), Salmonella enteritidis (KCTC 12021), Salmonella typhimurium (KCTC 2515), Enterobacter aerogenes (KCTC 2190), and Escherichia coli (ATCC 8739). The inhibition zone diameters were 20.3, $17.8,15.2,16.3,14.1,15.3,14.0,12.4$ and $12.1 \mathrm{~mm}$, respectively. The MIC values were $62.5,62.5,250,125$, $250,125,250,500$ and $500 \mu \mathrm{g} / \mathrm{mL}$, respectively. These findings suggest that FLJ volatile oil is a potential source of preservatives for the food or pharmaceutical industries. The antibacterial activities of FLJ against Bacillus cereus and Staphylococcus aureus were tested using the agar-well diffusion method in vitro. The inhibition zone diameters were 6.3 and $7.2 \mathrm{~mm}$, respectively; this activity might be closely associated with the existence of phenolic constituents [24]. Moreover, FLJ exhibited marked antibacterial activity against 14 strains, including Staphylococcus aureus, Streptococcus haemolyticus, Escherichia coli, Bacillus dysenteriae, Bacillus comma, Bacillus typhosus, Bacillus paratyphosus, Pseudomonas aeruginosa, Klebsiella pneumoniae, Bacillus tuberculosis, Streptococcus mutans, Bacillus adhaerens, Bacteroides melaninogenicus, and Haemophilus actinomycetemcomitans. FLJ extracts have also been found to inhibit $87.5 \%$ strains using MIC $25 \mathrm{mg} / \mathrm{mL}$ [25].

One study investigated the antimicrobial activity of FLJ water and alcohol extract. The MIC and MBC values for the water extract on Staphylococcus aureus were 19.25 and $38.50 \%$, respectively; the MIC and MBC values for the alcohol extract on Salmonella enteritidis were 9.80 and $19.60 \%$, respectively, and for Staphylococcus aureus were 19.60 and $39.20 \%$, respectively [26]. FLJ flavonoids also showed a strong antibacterial action, especially for methicillin-resistant Staphylococcus aureus (MIC $\leq 5 \mathrm{mg} / \mathrm{mL}$ ) [27]. These reports suggest that FLJ is a potent agent for treating various bacteria.

\section{Detoxifying: antiviral activity}

Several studies have demonstrated the antiviral activity of FF. FF aqueous extract showed antiviral activity against respiratory syncytial virus (RSV) with $\mathrm{IC}_{50} 50 \mu \mathrm{g} / \mathrm{mL}$ and $\mathrm{CC}_{50} 1000 \mu \mathrm{g} / \mathrm{mL}$ [28]. Wen et al. found that $80 \%$ ethanol extract of FF had a significant protective effect on MadinDarby canine kidney cells infected by the $\mathrm{H}_{1} \mathrm{~N}_{1}$ virus in a dose-dependent manner [29]. Li et al. [30] assessed the effects of forsythoside A on cell infection by avian infectious bronchitis virus; the data indicated that this compound prevented virus infection in vitro, but the mechanisms remain unclear.

Many studies have disclosed antiviral activity of FLJ, including anti-RSV, anti-HIV (human immunodeficiency virus), and anti-NDV (Newcastle disease virus) effects. Two studies used a cytopathologic effect (CPE) assay to test the antiviral activities against RSV of 44 medicinal herbs used for the treatment of respiratory tract infectious diseases in China [28, 31]. FLJ showed potent antiviral activity against RSV; the $\mathrm{IC}_{50}$ was $50.0 \mu \mathrm{g} / \mathrm{mL}$ and the selectivity index was more than 20.0. FLJ extract and chlorogenic acid had significant anti-cytomegalovirus activity, and the $0 \%$ toxic dose, minimum effective concentration, and therapeutic index (TI) of these two composites for human cytomegalovirus were $3000 \mu \mathrm{g} / \mathrm{mL}$, $3000 \mu \mathrm{g} / \mathrm{mL}, 1$ and $100 \mu \mathrm{g} / \mathrm{mL}, 1 \mu \mathrm{g} / \mathrm{mL}, 100$, respectively [32]. In in vitro tests, FLJ extract showed 104 and 72 times the TI for anti-herpes simplex virus-1 $\mathrm{F}$ and anti-herpes simplex-1 to acyclovir. Regarding the caviid beta-herpes virus 1, FLJ showed significant inhibition of the duplication of guinea pig cytomegalovirus at the cell level; the TI and the inhibitory duplication index were 100 and $2.61 \mu \mathrm{g} / \mathrm{mL}$, respectively [33]. The anti-virus $\left(\mathrm{H}_{9} \mathrm{~N}_{2}\right)$ and anti-avian influenza virus (least effective dose $[\mathrm{LED}]=3.90 \mathrm{mg} / \mathrm{mL}$, in vitro) activities of FLJ flavones have also been tested [34]. In Vero cells, three different extracts of FLJ, including volatile oil (P1), chlorogenic acids extract (P2), and flavones extract (P3), were tested for antiviral activity against the pseudorabies virus (PRV) and NDV. At doses of 232.7, 116.35, 58.18, and $29.09 \mu \mathrm{g} / \mathrm{mL}$, the P1 interdiction rates for PRV and NDV were $40.13 \%, 17.83 \%, 13.16 \%, 2.24 \%$ and $75.40 \%$, $32.01 \%, 12.05 \%, 2.34 \%$ on the CPE, respectively, and the LEDs of P1 for PRV and NDV were 232.7 and $232.7 \mu \mathrm{g} / \mathrm{mL}$, respectively. The $\mathrm{P} 2$ interdiction rates $(3.125,1.563,0.781$, and $0.391 \mathrm{mg} / \mathrm{mL})$ for PRV and NDV were $63.74 \%, 46.27 \%, 13.10 \%, 3.51 \%$ and $65.23 \%, 36.71 \%, 32.61 \%, 28.96 \%$ on the CPE, respectively. The P3 interdiction rates $(1.954,0.977,0.489$, and $0.244 \mathrm{mg} / \mathrm{mL}$ ) for PRV and NDV were $94.00 \%, 78.42 \%$, $42.30 \%, 3.36 \%$ and $78.07 \%, 27.63 \%, 16.37 \%, 6.73 \%$, respectively. For P2 and P3, the LEDs against PRV were 0.997 and $3.097 \mathrm{mg} / \mathrm{mL}$, respectively and against NVD, they were 0.781 and $1.563 \mathrm{mg} / \mathrm{mL}$, respectively. These studies suggest that FLJ extracts decrease CPE lesions and neutralize viruses in a dose-dependent manner, inhibiting viruses directly and promoting cell antivirus responses [35].

Several FLJ tannins have also been investigated; 3,5-di$\mathrm{O}$-caffeoylquinic acid and methyl 3,5-di-O-caffeoylquinic 
acids had a strong inhibitory effect on HIV-1 reverse transcriptase (RT) and human DNA polymerase- $\alpha$ (HDNAP$\alpha)$ [36]. The $\mathrm{IC}_{50}$ ratio of these two compounds for HIV-1 RT and HDNAP- $\alpha$ was 2.0 and 2.2, respectively. 3,4-di-Ocaffeoylquinic acid and methyl 3,4-di-O-caffeoylquinic acid exhibited higher inhibitory effects on HDNAP- $\alpha$ than on HIV-1 RT [36]. Thirteen other caffeoylquinic acids isolated from FLJ, including caffeic acid and caffeic acid methyl ester, were also found to show antiviral activities against respiratory viruses [37]. FLJ extract showed an obvious therapeutic action on mice infected with influenza A virus pneumonia [31]. The lung indexes of the FLJ group and the ribavirin group were significantly lower than in the model group, but there was no significance difference between the two treatment groups. FLJ extract reduced histopathological changes, viral duplication, and the contents of influenza virus nucleic acid compared with the model group. The tumor necrosis factor- $\alpha$ (TNF- $\alpha)$ and IL- $1 \beta$ expressions of the FLJ and the ribavirin groups were significantly lower than those of the model group. The FLJ chemical principles for antiviral activity were identified as chlorogenic acids, flavones, tannins, and volatile oil [31].

\section{Detoxifying: antitumor activity}

The apoptosis mechanisms induced by photodynamic therapy (PDT) in lung CH27 carcinoma cells, cultured with FLJ alcohol extract as a photosensitizer, have been explored. This extract exhibited significant photocytotoxicity in $\mathrm{CH} 27$ cells at a concentration range of $50-150 \mu \mathrm{g} / \mathrm{mL}$, with light doses of $0.4-1.2 \mathrm{~J} / \mathrm{cm}^{2}$. Apoptosis induced by PDT combined with FLJ extract was accompanied by DNA condensation, externalization of phosphatidylserine, and formation of apoptotic bodies [38]. The p38associated pathway might be involved in apoptosis induced by PDT with FLJ in $\mathrm{CH} 27$ cells. In another study, FLJ extract induced $\mathrm{CH} 27$ cell apoptosis via protein expression change and distribution of heat shock protein 27. Treatment with FLJ aqueous extract $(100 \mu \mathrm{g} / \mathrm{mL})$ was associated with increased stimulatory phosphorylation of c-Jun amino-terminal kinase and p38 in HepG2 cells, similar to the mitogen-activated protein kinase activation profile of protocatechuic acid [39]. This aqueous extract also decreased the viability of HepG2 cells to $50 \%$ and triggered HepG2 cell death in a c-Jun amino-terminal kinase-dependent manner.

\section{Heating clearing: anti-inflammatory activity}

Inflammation prevents infection through production of pro-inflammatory cytokines and generation of inflammatory mediators in response to microbial products [40]. Dysregulation of inflammation has an adverse effect on the body. Although modern anti-inflammatory drugs can bring relief, new kinds of microorganisms and the emergence of drug-resistant strains have resulted in significant morbidity and mortality. In the past few decades, more attention has been focused on the anti-inflammatory effect of CM herbs, especially heat-clearing herbs [41].

Many studies have demonstrated the anti-inflammatory action of FF. FF was found to exhibit platelet-activating factor antagonistic activity and inducible nitric oxide synthase inhibitory activity [42]. An FF methanol extract and its hexane fraction showed anti-inflammatory and analgesic activity against carrageenan-induced edema, cotton pellet-induced granuloma, and acetic acid-induced vascular permeability [43]. FF extract inhibited 5-lipoxygenase and elastase with the same $\mathrm{IC}_{50}$ values of $80 \mu \mathrm{g} / \mathrm{mL}$ [44]. FF ethanol extract also inhibited the secretion of the cytokine RANTES from virus-infected human bronchial epithelial cells [45]. These findings suggest that FF possesses anti-inflammatory activity through multiple target signaling pathways and multiple mechanisms of action.

Both in vivo and in vitro studies have shown that FLJ extract can inhibit various inflammatory reactions and suppress various inflammatory factors. Xu et al. [46] evaluated the anti-inflammatory property of FLJ aqueous extract in A549 cells; the extract directly inhibited both COX-1 and COX-2 activity, and IL-1-induced expression of COX-2 protein and mRNA. Kang et al. [47] examined the effect of FLJ water fraction on trypsin-induced mast cell activation. After stimulation with trypsin $(100 \mu \mathrm{M})$, FLJ water fraction inhibited TNF- $\alpha$ secretion, tryptase mRNA expression, and trypsin-induced extracellular signal-regulated kinase phosphorylation in a dosedependent manner; however, it did not affect trypsin activity even at $1000 \mu \mathrm{g} / \mathrm{mL}$. These studies indicate that FLJ might inhibit trypsin-induced mast cell activation through the inhibition of extracellular signal-regulated kinase phosphorylation rather than by inhibition of trypsin activity. One study evaluated the anti-inflammatory activity of $n$-butanol (4.2\% based on the dry weight [DW]) FJL fraction [48]. At a $400 \mathrm{mg} / \mathrm{kg}$ oral dose, it showed significant anti-inflammatory activities against arachidonic acid ear edema, croton-oil ear edema, carrageenan paw edema, and rat cotton pellet granulomatous and adjuvant-induced arthritis inflammation models in mice and rats; the inhibition rates were $27 \%, 23 \%$, $26 \%, 18 \%$, and $42 \%$, respectively and the inhibition rates for the positive drug aspirin $(100 \mathrm{mg} / \mathrm{kg})$ were $27 \%, 13 \%, 13 \%, 0 \%$, and $58 \%$, respectively.

FLJ water extract showed an anti-inflammatory effect on proteinase activated receptor 2 (PAR2)-mediated mouse paw edema; at doses of 50,100, and $200 \mathrm{mg} / \mathrm{kg}$, it significantly inhibited paw thickness change and vascular permeability induced by PAR2 (inhibition rates: $41.8 \%$, $69.1 \%, 70.9 \%$, and $40.2 \%, 69.7 \%, 68.8 \%$, respectively). FLJ water extracts $(100 \mathrm{mg} / \mathrm{kg})$ also significantly inhibited PAR2 agonist-induced myeloperoxidase (MPO) activity 
and TNF- $\alpha$ expression in paw tissue [49]. Tae et al. [50] used the supercritical $\mathrm{CO}_{2}$ extraction process to obtain $1.08 \%$ volatile oil from FLJ; pharmacological studies suggested a potent anti-inflammatory effect of the volatile oil on the ear-swelling model in mice. These reports indicate that FLJ is a safe, mild anti-inflammatory agent for treating various inflammatory disorders.

\section{Heat clearing: antioxidant activity}

Excessive reactive oxygen species result in significant damage to biological structures necessary to cellular integrity and survival. CM heat-clearing herbs are an important source of antioxidant agents. A study using a 1-diphenyl2-picrylhydrazyl (DPPH) free radical scavenging experiment found that the $\mathrm{CH}_{2} \mathrm{Cl}_{2}$ fraction of $F$. suspensa exerted the strongest scavenging activity and suggested that forsythialan $\mathrm{A}$ and phillygenin $\mathrm{F}$ are the major antioxidant constituents [51, 52]. Zhang et al. [53] studied the role of forsythoside $\mathrm{A}$ in the elimination of reactive oxygen species and discussed the relationship between structure and activity using quantum chemical calculation. The results showed that the $\mathrm{A}$ and $\mathrm{B}$ rings in forsythoside $\mathrm{A}$ were active parts of its antioxidant activity, and the structure of phenolic hydroxyl groups in opposition caused higher antioxidant activity. Moreover, lianqiaoxinoside $\mathrm{B}$ and forsythoside $\mathrm{H}$ showed nearly the same antioxidant activities. These phenylethanoid glycosides have two ortho-substituting hydroxyl groups in both the caffeoyl and phenylethanoid moieties, which could be an important factor in their high antioxidant activity [54]. Lignans obtained from FF could protect human high-density lipoprotein against lipid peroxidation. In one study, they inhibited the generation of thiobarbituric acid-reactive substances in a dose-dependent manner with $\mathrm{IC}_{50}$ values from 8.5 to $18.7 \mu \mathrm{M}$. Among these lignans, some exerted an inhibitory effect against the $\mathrm{Cu}^{2+}$-induced lipid peroxidation of high-density lipoprotein, as shown by an extended lag time prolongation at a $3.0 \mu \mathrm{M}$ concentration [55]. The protective activity of $F$. suspensa against peroxynitrite (ONOO)-induced cellular damage was investigated, and its active components, phillygenin and 8-hydroxypinoresinol, were identified. These two compounds significantly reduced cell injury by 3-morpholinosydnonimine, an ONOO generator. The hydroxyl substituents of these lignans on the phenyl moieties may contribute to the antioxidant activity [56].

The antioxidant action of FLJ has been widely investigated. The FLJ ethyl acetate fraction exhibited marked scavenging/inhibitory activities with $\mathrm{IC}_{50}$ values of $4.37,27.58 \pm$ $0.71,0.47 \pm 0.05$, and $12.13 \pm 0.79 \mu \mathrm{g} / \mathrm{mL}$ in the DPPH radical, total reactive oxygen species, hydroxyl radical $(-\mathrm{OH})$, and peroxynitrite $\left(\mathrm{ONOO}^{-}\right)$assays, respectively [57]. The main compounds of the ethyl acetate fraction-luteolin, caffeic acid, protocatechuic acid, and luteolin 7-O-d- glucopyranoside - also evidenced marked scavenging activities, with $\mathrm{IC}_{50}$ values of $2.08-11.76 \mu \mathrm{M}$ for $\mathrm{DPPH}$ and 1.47-6.98 $\mu \mathrm{M}$ for $\mathrm{ONOO}^{-}$[57]. The Trolox equivalent antioxidant capacity values and total phenolic content for methanolic extracts of FLJ have been demonstrated as $589.1 \mu \mathrm{mol}$ Trolox equivalent/100 g DW and 3.63 gallic acid equivalent/100 g DW [58]. These studies suggest that FLJ is a potential natural antioxidant and beneficial chemopreventive agent. The antioxidant activity of polysaccharides with different molecule weights separated from FLJ by ultrafiltration was also studied. The reducing power of the polysaccharides had a direct correlation with antioxidant activity and concentration of certain plant extracts, and the ultrafiltration fraction had a significant inhibitory effect on superoxide radicals generated in a phenazine methosulphate/hydrogenated nicotinamide adenine dinucleotide/ nitroblue tetrazolium system. Administered to rats, crude polysaccharide extracts $(50-400 \mathrm{mg} / \mathrm{kg}$ ) were found to reduce lipid peroxidation malondialdehyde content, improve glutathione peroxidase and catalase activity, and significantly enhance superoxide dismutase activity in serum and tissue [59].

\section{Limitations of this review}

Few studies demonstrated a synergistic or additive effect for this herb pair. Comparable studies, using both single herbs (FLJ and FF) and the FLJ-FF herb pair, should be conducted to investigate possible synergistic or additive effects. Interdisciplinary research is needed to identify minor bioactive components using phytochemical studies, to generate reliable cell and animal models using pharmacological studies, and to elucidate underlying mechanisms using molecular biological studies.

All pharmacological studies reviewed here used in vitro or in vivo models; there was no clinical investigation of the effects of the FLJ-FF herb pair (or of single herbs). Thus, this review provides no clinical evidence for the bioactivities of FLJ and FF. In addition, some of the pharmacological targets of the FLJ-FF herb pair are still unknown.

\section{Conclusion}

The main bioactive components of FLJ and FF are flavonoids, organic acids, volatile oil, phenylethanoid glycosides, lignans, and triterpenoids. These show clear pharmacological effects, including antibacterial, antiviral, anti-inflammatory, antitumor, and antioxidant actions.

\section{Abbreviations}

CM: Chinese Medicines; FLJ: Flos Lonicerae japonicae; FF: Forsythiae fructus; MIC: Minimum inhibitory concentration; MBC: Minimum bactericidal concentration; RSV: Respiratory syncytial virus; HIV: Human Immunodeficiency virus; NDV: Newcastle disease virus; CPE: Cytopathologic effect; SI: Selectivity index; TNF-a: Tumor necrosis factor-a; IL-1ß: interleukin-1B; TI: Therapeutic index; PDT: Photodynamic therapy; LED: Least effective dose; PRV: Pseudo rabies virus; PAR2: Proteinase activated receptor 2; MPO: Myeloperoxidase; DPPH: 1-diphenyl-2-picrylhydrazyl. 


\section{Competing interests}

The authors declare that they have no competing interests.

\section{Authors' contributions}

YG, LL and YW conducted this review. YG, LL and YW wrote the manuscript. All the authors read and approved the final version of the manuscript.

\section{Acknowledgement}

Financial support by the Macao Science and Technology Development Fund (074/2012/A3) and the Research Fund of University of Macau (MRG013/WYT/ 2013/ICMS, MYRG2014-00020-ICMS-QRCM and One-time Special Fund for Ph.D Support to LL) are gratefully acknowledged.

Received: 17 August 2014 Accepted: 25 June 2015

Published online: 02 July 2015

\section{References}

1. Wang S, Hu Y, Tan W, Wu X, Chen R, Cao J, et al. Compatibility art of traditional Chinese medicine: from the perspective of herb pairs. J Ethnopharmacol. 2012;143:412-23.

2. Wang L, Zhang J, Hong Y, Feng Y, Chen M, Wang Y. Phytochemical and pharmacological review of da chuanxiong formula: a famous herb pair composed of chuanxiong rhizoma and gastrodiae rhizoma for headache. Evid Based Complement Altern Med. 2013;2013:425369.

3. Chan K. Chinese medicinal materials and their interface with Western medical concepts. J Ethnopharmacol. 2005;96:1-18.

4. Xu D. Mutual understanding between traditional Chinese medicine and systems biology: gaps, challenges and opportunities. Inter J Func Inform Personal Med. 2009;2:248-60.

5. Wang H, Cheng J, Zhang WG. Pharmacodynamic compariason on the mixed decoction and the separated granule of Erchen Tang. Zhong Guo Yi Yuan Yao Wu Za Zhi. 2001;12:721-3.

6. Yu F, Takahashi T, Moriya J, Kawaura K, Yamakawa J, Kusaka K, et al. Traditional Chinese medicine and Kampo: a review from the distant past for the future. J Int Med Res. 2006;34:231-9.

7. Nishibe S, Chiba M, Hisada S. Studies on the Chinese crude drug "Forsythiae fructus". I. On the constituents of Forsythiae fructus on the market. Yakugaku Zasshi. 1977:97:1134-7.

8. Yu JS, Ho CH, Hsu YC, Wang JJ, Hsien CL. Traditional Chinese medicine treatments for upper respiratory tract infections/common colds in Taiwan. Eur J Integr Med. 2014;6:538-44.

9. Commission CP: Pharmacopoeia of the People's Republic of China. Committee, C. P; 2010.

10. Lin $Z X$, Lin $L, Y u ~ H$, Tang GH, Xu YJ, He DP, et al. A retrospective study on clinical features of and treatment methods for 77 severe cases of SARS. Am J Chin Med. 2003;31:821-39.

11. Chen XY, Wu TX, Liu GJ, Wang Q, Zheng J, Wei J, et al. Chinese medicinal herbs for influenza. Cochrane Database Syst Rev. 2007;17:CD004559.

12. Rahman A, Kang SC. In vitro control of food-borne and food spoilage bacteria by essential oil and ethanol extracts of Lonicera japonica Thunb. Food Chem. 2009;116:670-5.

13. Li Q, Feng WS. Recent development of chemical components of studies Fructus forsythiae. He Nan Zhong Yi Xue Yuan Xue Bao. 2005;20:78-80.

14. Ma YY, Zhang ZW, Li HW, Sun JH, Xu CY, Wu GJ. Effects of forsythoside A on the expression of IFN- $a$ and Mx1. Zhong Guo Nong Ye Ke Xue. 2010;43:3237-43.

15. Han J, Ye M, Guo H, Yang M, Wang B, Guo D. Analysis of multiple constituents in a Chinese herbal preparation Shuang-Huang-Lian oral liquid by HPLC-DAD-ESI-MS n. J Pharm Biomed Anal. 2007:44:430-8.

16. Chen YY, Xiang JJ, Xu MM, Tao LL, Gu WW. Studies on chemical constituents of Forsythia suspensa (Thunb) Vahl. Zhong Guo Zhong Yao Za Zhi. 1999;24:296-319.

17. Lou ZX, Wang HX, Zhu S, Ma CY, Wang ZP. Antibacterial activity and mechanism of action of chlorogenic acid. J Food Sci. 2011;6:398-403.

18. Li YH, Zheng FJ, Huang Y, Zhong XG, Guo MZ. Synergistic anti-inflammatory effect of Radix Platycodon in combination with herbs for cleaning-heat and detoxification and its mechanism. Chin J Inter Med. 2013;19:29-35.

19. Duan HY, Ma C. Experimental study on pyretolysis mechanism of compatible application of Japanese Honeysuckle flower and weeping Forsythia fruit. Modern J Integrated Traditional Chin Western Med. 2009;18:1214-6.
20. Wang HJ, Zhou TH, Liu XG, Wang JL, Liu Y. Screening optimal dose ratio of Yinqiaotiangan compound by method of synergic index. Progress Veter Med. 2011;32:58-62.

21. Endo K, Takahashi K, Abe T. Structure of forsythoside A, an antibacterial principle of Forsythia suspensa leaves. Heterocycles. 1981;8:1311-4.

22. Endo K, Hikino H. Validity of oriental medicine. Part 44. Structures of forsythoside C and D, antibacterial principles of Forsythia suspensa fruits. Heterocycles. 1982;19:2033-6.

23. Wei X, Zhou X, Ma H. The effect essential oil of Forsythia suspense (Thunb.) Vahl. (FSV) on fungi in vitro growth and oxidation. Nat Prod Res Dev. 2005;17:625-6.

24. Bin S, Cai YZ, Brooks JD, Corke H. The in vitro antibacterial activity of dietary spice and medicinal herb extracts. Int J Food Microbiol. 2006;117:112-9.

25. Song H, Qiu J, Wang Z, Zhang Q. Research on the in vitro growth inhibition effect of Lonicera japonica Thunb. (LJT) on bacteria. Shi Zheng Guo Yi Guo Yao. 2003;14:269-72.

26. Xu K. Study on antimicrobial activity of extracts from Lonicera japonica Thunb. An Hui Nong Ye Ke Xue. 2010;27:14935-6.

27. Tang M. Study of Isolation and Biological Effects of Active Flavonoid Components Extracted from Lonicera Japonica, Thesis, The Third Military Medical University. 2008.

28. Ma SC, Du J, But P, Deng XL, Zhang YW, Ooi V, et al. Antiviral Chinese medicinal herbs against respiratory syncytial virus. J Ethnopharmacol. 2002;79:205-11.

29. Wen S, Huifu $X$, Hao H. Effects of the extract of Forsythia suspensa on influenza $A H_{1} N_{1}$ infection in vitro. J Med Plant Res. 2010;4:1455-8.

30. Li H. Forsythoside a inhibits the avian infectious bronchitis virus in cell culture. Phytother Res. 2011;25:338-42.

31. Xi Q. Experimental study on the intervention of active component of Lonicerae Powder on immune cytokines of influenza viral pneumonia in mice, Thesis, TCM University of Liaoning. 2008.

32. Chen J, Fang J, Wan J, Feng L, Zhang Y. An in vitro study of the anticytomegalovirus effect of chlorogenic acid. Yi Yao Dao Bao. 2009;28:1138-40.

33. Wang XR, Chen SH, Qiao FY. Experimental study of honeysuckle flower against guinea pig cytome galovirus in vitro. Zhong Guo Fu You Bao Jian. 2005;17:2241-3.

34. Wang X, Zhao A, Jia W. Anti-influenza agents from plants and traditional Chinese medicine. Phytother Res. 2006;20:335-41.

35. Wang LQ. Studies on Antiviral Effect and Immunopotentiating Activity of Lonicera japonica Thunb. and flos lonicerae in vitro, Thesis, Agricultural University of Henan. 2008.

36. Chang CW, Lin MT, Lee SS, Liu K, Hsu FL, Lin JY. Differential inhibition of reverse-transcriptase and cellular DNA polymerase-alpha Aactivities by lignans isolated from Chinese herbs, phyllanthus-myrtifolius moon, and tannins from lonicera-japonica Thunb and castanopsis-hystrix. Antiviral Res. 1995;27:367-74.

37. Ma S, Paul B, Vincent O, Spencer HS. Determination of the antiviral caffeoyl quinic acids isolated from Lonicera japonica Thunb. Yao Wu Fen Xi Za Zhi. 2005; $25: 751$.

38. Leung HWC, Hour MJ, Chang WT, Wu YC, Lai MY, Wang MY, et al. P38associated pathway involvement in apoptosis induced by photodynamic therapy with Lonicera japonica in human lung squamous carcinoma $\mathrm{CH} 27$ cells. Food Chem Toxicol. 2007;46:3389-400.

39. Yip ECH, Chan ASL, Pang H, Tam YK, Wong YH. Protocatechuic acid induces cell death in HepG2 hepatocellular carcinoma cells through a c-Jun Nterminal kinase-dependent mechanism. Cell Biol Toxicol. 2006;22:293-302.

40. Coussens LM, Werb Z. Inflammation and cancer. Nature. 2002;4:860-7.

41. Shang X, Pan H, Li M, Miao X, Ding H. Lonicera japonica Thunb.: Ethnopharmacology, phytochemistry and pharmacology of an important traditional Chinese medicine. J Ethnopharmacol. 2011;138:1-21.

42. Iwakami S, Wu JB, Ebizuka Y, Sankawa U. Platelet activating factor(Paf) antagonists contained in medicinal-plants - lignans and sesquiterpenes. Chem Pharm Bull (Tokyo). 1992;40:1196-8.

43. Ozaki Y, Rui J, Tang YT. Antiinflammatory effect of Forsythia suspensa (Vahl) and its active principle. Bio Pharm Bull. 2000;23:365-7.

44. Prieto JM, Recio MC, Giner RM, Máñez S, Giner-Larza EM, Ríos JL. Influence of traditional Chinese anti-inflammatory medicinal plants on leukocyte and platelet functions. J Pharm Pharmacol. 2003;55:1275-82.

45. Ko HC, Wei BL, Chiou WF. The effect of medicinal plants used in Chinese folk medicine on RANTES secretion by virus-infected human epithelial cells. J Ethnopharmacol. 2006;107:205-10. 
46. Xu Y, Oliverson BG, Simmons DL. Trifunctional inhibition of COX-2 by extracts of Lonicera japonica: Direct inhibition, transcriptional and post-transcriptional down regulation. J Ethnopharmacol. 2006;111:667-70.

47. Kang $\mathrm{OH}$, Choi YA, Park HJ, Lee JY, Kim DK. Inhibition of trypsin-induced mast cell activation by water fraction of Lonicera japonica. Arch Pharm Res. 2004;27:1141-6.

48. Lee SJ, Son KH, Chang HW, Kang SS, Kim HP. Antiinflammatory activity of Lonicera japonica. Phytother Res. 1998;12:445-7.

49. Lee JH, Ko WS, Kim YH, Kang HS, Kim HD, Choi BT. Anti-inflammatory effect of the aqueous extract from Lonicera japonica flower is related to inhibition of NF-kappaB activation through reducing I-kappaBalpha degradation in rat liver. Int J Mol Med. 2001;7:79-83.

50. Tae J, Han SW, Yoo JY, Kim JA, Kang OH, Baek OS, et al. Anti-inflammatory effect of Lonicera japonicain proteinase-activated receptor 2-mediated paw edema. Clin Chim Acta. 2002;330:165-71.

51. Zeng ZK, Li QY, Piao XS, Liu JD, Zhao PF, Xu X, et al. Forsythia suspensa extract attenuates corticosterone-induced growth inhibition, oxidative injury and immune depression in broilers. Poultry Sci. 2014;93:1-8.

52. Lu T, Piao XL, Zhang Q, Wang D, Piao XS, Kim SW. Protective effects of Forsythia suspensa extract against oxidative stress induced by diquat in rats. Food Chem Toxicol. 2009:48:764-70.

53. Zhang LW, Zhao CG, Wang JD, Yang P. Inhibition of elastase by forsythiaside from Fructus Forsythiae. Hua Xue Yan Jiu Yu Ying Yong. 2002;2:119-221.

54. Kuang HX, Xia YG, Liang J, Yang BY, Wang QH. Lianqiaoxinoside B, a novel caffeoyl phenylethanoid glycoside from Forsythia suspensa. Molecules. 2010;16:5674-81.

55. Chang MJ, Hung TM, Min BS, Kim JC, Woo MH, Choi JS, et al. Lignans from the fruits of Forsythia suspensa (Thunb.) Vahl protect high-density lipoprotein during oxidative stress. Biosci Biotechnol Biochem. 2008;72:2750-5.

56. Piao $\mathrm{XL}$, Cho EJ, Jang MH, Cui J. Cytoprotective effect of lignans from Forsythia suspensa against peroxynitrite-induced LLC-PK1 cell damage. Phytother Res. 2009;23:938-42.

57. Choi CW, Jung HA, Kang SS, Choi JS. Antioxidant constituents and a new triterpenoid glycoside from Flos Lonicerae. Arch Pharm Res. 2007;30:1-7.

58. Cai Y, Luo Q, Sun M, Corke H. Antioxidant activity and phenolic compounds of 112 traditional Chinese medicinal plants associated with anticancer. Life Sci. 2004:74:2157-84.

59. Li S, Han Q, Qiao C, Song J, Cheng CL, Xu H. Chemical markers for the quality control of herbal medicines: an overview. Chin Med. 2008:3:7.

60. Huang L, Lu Z, Li J, Zhou B. Studies on the chemical constituents of Japanese honeysuckle (Lonicera japonica). Zhong Cao Yao. 1996;11:645-7.

61. Iwahashi H, Negoro Y, Ikeda A, Morishita H, Kido R. Inhibition by chlorogenic acid of haematin-catalysed retinoic acid 5,6-epoxidation. Biochem J. 1986:239:641-6.

62. Qi LW, Chen CY, Li P. Structural characterization and identification of iridoid glycosides, saponins, phenolic acids and flavonoids in Flos Lonicerae Japonicae by a fast liquid chromatography method with diode-array detection and time-of-flight mass spectrometry. Rapid Commun Mass Spectrom. 2009;23:3227-42.

63. Lee EJ, Kim JS, Kim HP, Lee JH, Kang SS. Phenolic constituents from the flower buds of Lonicera japonica and their 5-lipoxygenase inhibitory activities. Food Chem. 2010;120:134-9.

64. Ren MT, Chen J, Song Y, Sheng LS, Li P, Qi LW. Identification and quantification of 32 bioactive compounds in Lonicera species by high performance liquid chromatography coupled with time-of-flight mass spectrometry. J Pharm Biomed Anal. 2008;48:1351-60

65. Peng L-Y, Mei S-X, Jiang B, Zhou H, Sun H-D. Constituents from Lonicera japonica. Fitoterapia. 1999;71:713-5

66. Lou HX, Lang WJ, Lu MJ. Water soluble constituents from Japanese honeysuckle (Lonicera japonica). Zhong Cao Yao. 1996;04:195-9.

67. Kameoka H, Miyazawa M, Haze K. 3-ethyl-7-hydroxyphthalide from Forsythia japonica. Phytochem. 1975;14:1676-7.

68. Yumin G, Huijun M. Studies on the chemical constituents of Japanese honeysuckle (Lonicera japonica). Zhong Cao Yao. 1995;11:2-6.

69. Pan ZT, Rui E, Bizli HJ, Ping LI. Flavonoids from aerial parts of Lonicera chrysantha. Zhong Guo Yao Xue Za Zhi. 2006;41:741-3.

70. Lee S, Shin E, Son K, Chang H, Kang S, Kim H. Anti-inflammatory activity of the major constituents of Lonicera japonica. Arch Pharm Res. 1995;18:133-5.

71. Son KH, Park JO, Chung KC, Chang HW. Flavonoids from the aerial parts of Lonicera japonica. Arch Pharm Res. 1992;15:365-70.
72. Kumar N, Singh B, Gupta AP, Kaul VK. Lonijaposides, Novel Cerebrosides from Lonicera japonica, vol. 62. 2006. p. 4317-22.

73. Machida K, Asano J, Kikuchi M. Analysis of the components of Lonicera species.3. caeruleoside-A and caeruleoside-B, bis-iridoid glucosides from Lonicera-Caerulea. Phytochem. 1995;39:111-4.

74. Song Y, Li S, Wu M, Li H, Li P. Qualitative and quantitative analysis of iridoid glycosides in the flower buds of Lonicera species by capillary high performance liquid chromatography coupled with mass spectrometric detector. Anal Chim Acta. 2006;564:8-18.

75. Son KH, Jung KY, Chang HW, Kim HP, Kang SS. Triterpenoid saponins from the aerial parts of Lonicera japonica. Phytochem. 1994;35:1005-8.

76. Kakuda R, Imai M, Yaoita Y, Machida K, Kikuchi M. Secoiridoid glycosides from the flower buds of Lonicera japonica. Phytochem. 2000;55:879-81.

77. Li HJ, Li P, Wang MC, Ye WC. A new secoiridoid glucoside from Lonicera japonica. Chin J Nat Med. 2003;1:132-3.

78. Yang Y, Song WX, Zhu CG, Lin S, Zhao F, Wu XL, et al. Homosecoiridoids from the flower buds of Lonicera japonica. J Nat Prod. 2011;74:2151-60.

79. Machida K, Sasaki H, lijima T, Kikuchi M. Studies on the constituents of Lonicera species. XVII. New iridoid glycosides of the stems and leaves of Lonicera japonica Thumb. Chem Pharm Bull (Tokyo). 2002;50:1041-4.

80. Kawai H, Kuroyanagi M, Umehara K, Ueno A, Satake M. Studies on the saponins of Lonicera japonica Thumb. Chem Pharm Bull (Tokyo). 1988;36:4769-75

81. Chen CX, Wang WW, Ni W, Chen NY. Triterpenoid glycosides from the Lonicera japonica. Acta Metallurgica Sinica. 2000;22:1-3.

82. Kwak WJ, Han CK, Chang HW, Kim HP, Kang SS, Son KH. Loniceroside C, an antiinflammatory saponin from Lonicera japonica. Chem Pharm Bull (Tokyo). 2003:51:333-5.

83. Lin LM, Zhang XG, Zhu JJ, Gao HM, Wang ZM, Wang WH. Two new triterpenoid saponins from the flowers and buds of Lonicera japonica. J Asian Nat Prod Res. 2008;10:925-9.

84. Endo K, Seya K, Hikino H. Structure and enantioselective synthesis of suspenol, a new polyol of Forsythia suspensa. Tennen Yuki Kagobutsu Toronkai Koen Yoshishu. 1987;29:660-7.

85. Nishibe S, Okabe K, Tsukamoto H, Sakushima A, Hisada S, Baba H, et al. Studies on the Chinese crude drug "Forsythiae Fructus". VI. The structure and antibacterial activity of suspensaside isolated from Forsythia suspensa. Chem Pharm Bull (Tokyo). 1982;30:4548-53.

86. Wang FN, Ma ZQ, Liu Y, Guo YZ, Gu ZW. New phenylethanoid glycosides from the fruits of Forsythia suspense (Thunb.) vahl. Molecules. 2009;14:1324-31.

87. Qu H. Chemical constituents of Forsythia suspensa and bioactivity study, Thesis, Northwest University. 2008.

88. Guo H. Studies on the Chemical Constituents of Forsythia suspensa, Thesis, Peking University. 2006.

89. Liu DL, Zhang Y, Xu SX, Xu Y. Phenylethanoid glycosides from Forsythia suspensa Vahl. Zhong Guo Yao Xue Za Zhi. 1998;7:103-5.

90. Ming DS. Studies on the chemical constituents and pharmacological activities on Forsythia suspensa and Valeriana jatamansi Jones, Thesis, Peking Union Medical College. 1998.

91. Seya K, Endo K, Hikino H. Structures of rengyosides A, B and C, three glucosides of Forsythia suspensa fruits. Phytochem. 1989:28:1495-8.

92. Hu WY, Luo SD. The isolation and identification of three acetylated triterpenoid from Forsythia suspensa. Zhong Cao Yao. 1991;22:147-52.

93. Fang Y, Zou GA, Liu YW. Chemical constituents from Forsythia suspensa (Thunb.) Vahl. Chin J Nat Med. 2008;6:235-6.

94. Yin JG, L G. Modern Research and Clinical Application of Chinese Medicine (I). Beijing: Science Press, 1993. p. 356-8.

95. Lee JS, Min BS, Bae KH. Cytotoxic constituents from the Forsythiae fructus against L1210 and HL60 cells. Yakhak Hoechi. 1996:40:462-7.

96. Rouf AS, Ozaki Y, Rashid MA, Rui J. Dammarane derivatives from the dried fruits of Forsythia suspensa. Phytochemistry. 2001;56:815-8.

97. Takizawa Y, Suzuki E, Mitsuhashi T. Studies on naturally occurring antioxidant (I): isolation and determination of natural phenolic antioxidants from Forsythia suspensa Vahl. Bull Tokyo Gakugei University. 1981;33:119-23.

98. Liu Y. Studies on the Chemical Constituents of the Extract with Water from Forsythia suspensa (Thunb.) Vahl, Thesis, Pharmaceutical University of Shenyang. 2003

99. Liu DL, Xu SX, Li HQ, Cui W, Fang B. Lignan glycosides of Forsythia suspensa vahl. Sheng Yang Yao Ke Da Xue Xue Bao. 1997;3:43-5.

100. Feng W, Li K, Zheng X. Studies on chemical constituents in Forsythia suspensa (Thunb.) Vahl. Zhong Guo Yao Xue Za Zhi. 2009;7:490-2. 
101. Piao XL, Jang MH, Cui J, Piao XS. Lignans from the fruits of Forsythia suspensa. Bioorg Med Chem Lett. 2008;18:1980-4.

102. Endo K, Seya K, Hikino H. Stereostructure of rengyol and isocengyol, phenylethanoids of Forsythia suspensa. Tetrahedron. 1987;43:2681-8

103. Wang W, Liu D, Xu S, Xiao F. A new compound in Forsythia suspensa Vahl. Sheng Yang Yao Ke Da Xue Xue Bao. 1998;16:138-45.

104. Endo K, Hikino H. Structures of rengyol, rengyoxide, and rengyolone, new cyclohexylethane derivatives from Forsythia suspensa fruits. Can J of Chem. 1984;62:2011-4.

105. Naghski JJ, Porter WLW, Couch JFJ. Isolation of rutin from two varieties of Forsythia. J Am Chem Soc. 1947;69:572.

106. Cui $Y$, Wang $Q$, Shi $X$, Zhang $X$, Sheng $X$, Zhang L. Simultaneous quantification of 14 bioactive constituents in Forsythia suspensa by liquid chromatography-electrospray ionisation-mass spectrometry. Phytochem Anal. 2010;21:253-60

107. Guo Q, Wang Z, Lin M, Xia BH. Researches on chemical constituents in medicinal plants in Genus Forsythiae. Chin J Exper Tradit Med Formula. 2009;5:74-8.

108. Dai SJ, Ren Y, Shen L, Zhang DW. New alkaloids from Forsythia suspensa and their anti-inflammatory activities. Planta Med. 2009;75:375-7.

109. Cai Q, Liu Y, Feng X. Studies on chemical constituents from seed of Forsythia suspensa. Chin Med Mat. 2009;11:1691-3.

110. Chen X, Beutler JA, MCCloud TG, Loehfelm A, Yang L, Dong H-F, et al. Tannic acid is an inhibitor of CXCL12 (SDF-1alpha)/CXCR4 with antiangiogenic activity. Clin Cancer Res. 2003;9:3115-23.

\section{Submit your next manuscript to BioMed Central and take full advantage of:}

- Convenient online submission

- Thorough peer review

- No space constraints or color figure charges

- Immediate publication on acceptance

- Inclusion in PubMed, CAS, Scopus and Google Scholar

- Research which is freely available for redistribution 